\title{
O ensino e aprendizagem dos objetos reta e desigualdades com o GrafEq: uma abordagem com vistas à Teoria dos Registros de Representação Semiótica
}

\author{
Fabrício Fernando Halberstadt - PPGEM\&EF/UFSM - ffhalberstadt@gmailcom \\ Leandra Anversa Fioreze - PPGEM\&EF/UFSM - UFRGS - leandra.fioreze@gmailcom
}

\begin{abstract}
Resumo: Este trabalho apresenta alguns resultados do delineamento de uma pesquisa de mestrado a qual teve por principal objetivo estudar o processo de compreensão de conceitos e propriedades da Geometria Analítica do Ensino Médio com o uso do software GrafEq. Como aporte teórico adotou-se a Teoria dos Registros de Representações Semióticas de Raymond Duval devido ao papel importante das representações na compreensão dos conceitos matemáticos. Com o intuito de propiciar a coordenação entre os registros de representação geométrico e algébrico da Geometria Analítica, as atividades que compõem a sequência didática foram planejadas com o uso do software GrafEq, permitindo que o aluno realizasse diversas experimentações envolvendo esses registros. Apresenta-se nesse trabalho uma análise sobre os resultados referentes a atividades elaboradas sobre os objetos reta e desigualdades e dinamizadas junto a turma de alunos do terceiro ano do Ensino Médio de uma escola da cidade de Santa Maria/RS. Os resultados apontam para a consolidação do reconhecimento desses objetos nos seus diferentes registros de representação semiótica, condição prioritária para a sua compreensão.
\end{abstract}

Palavras-chave: Registros de Representação Semiótica, geometria analítica, reta, desigualdades, GrafEq.

\section{The teaching and learning process of line and inequalities objects with GrafEq: An} approach based on Semiotic Representation Register Theory

\begin{abstract}
This work presents parts of the results from a master research which had as its objective studying the Analytic Geometry secondary school process of understanding concepts and proprieties with the use of software GrafEq. It has been based on the Semiotic Representation Register Theory from Raymond Duval due to its important role in representing the understanding of mathematical concepts. Aiming to coordinate the registration from geometric representation and algebraic Analytical Geometric, the activities which form the didactic sequence have been planned with the use of software GrafEq, allowing the student to perform several trials involving these records. The analysis of results related to activities elaborated about the line and inequalities and dynamised objects with students from the third year of secondary school from Santa Maria/RS is presented. The results point out the consolidation about the understanding of this object in its different semiotic representation registers, which is an important condition for its understanding.
\end{abstract}

Key-words: Semiotic Representation Register, analytic geometry, line, inequalities, GrafEq.

\section{Introdução}

Vivenciamos grandes feitos tecnológicos da humanidade, especialmente nas últimas décadas com a invenção e difusão da informática. Atualmente, temos à disposição diversas ferramentas tecnológicas que contribuem para o processo de ensino e aprendizagem da matemática à medida que permitem a elaboração de atividades nas quais as estratégias de resolução possibilitam um entendimento global de conceitos matemáticos que não seriam possíveis com as ferramentas tradicionais, tais como o lápis, o papel e o quadro (Notare, Fioreze, Halberstadt, 2015). Dentre as ferramentas tecnológicas disponíveis para o ensino da matemática, para o desenvolvimento desta pesquisa, escolhemos o software GrafEq.

O trabalho com o software GrafEq pode representar uma interessante oportunidade de abordar conteúdos matemáticos em sala de aula, principalmente no que se refere ao trabalho com geometria analítica e desigualdades. Por exemplo, pode-se pensar em atividades nas quais se propõem que os alunos façam a representação de imagens de obras de arte, ilusões de ótica, esculturas, elementos arquitetônicos de prédios históricos, etc. A figura 1 traz a representação da imagem do Planetário da Universidade Federal de Santa Maria (UFSM). 


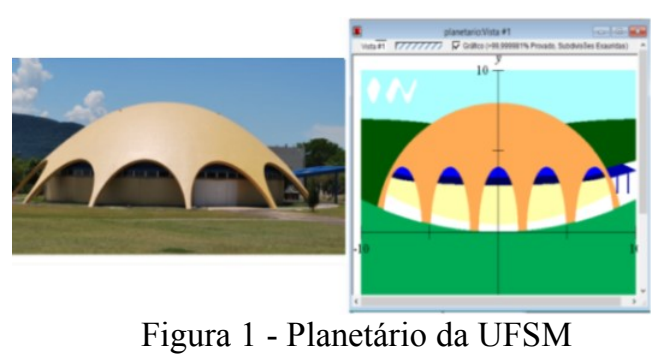

Para definir essas regiões é necessário que se defina um razoável número de relações com inequações envolvendo os seguintes objetos da geometria analítica: círculo, parábola, reta e elipse. A figura 2 apresenta três relações utilizadas na representação do Planetário.
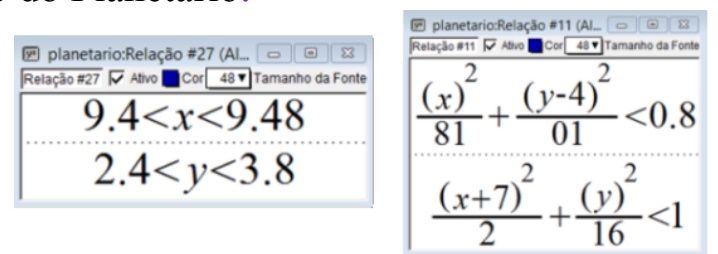

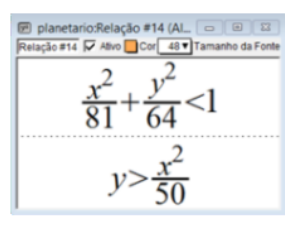

Figura 2 - Algumas relações utilizadas na representação do Planetário no GrafEq

Conforme Duval (2003, 2009, 2013), para que o aluno compreenda um objeto matemático é primordial que o reconheça nos seus diversos registros de representação semiótica e coordene esses registros. Nesse sentido, é interessante destacar a simultaneidade de experimentações que se pode fazer entre os registros algébrico e gráfico dos objetos matemáticos plotados no GrafEq, pois permanecem na janela principal do GrafEq tanto a janela com o registro algébrico como a janela com o registro gráfico. Parafraseando Notare e Gravina (2013), pode-se dizer que o trabalho com esse software pode representar um ganho de potencial semiótico.

Apresenta-se ao longo deste texto um recorte de uma pesquisa de mestrado em andamento realizada pelo seu autor o qual tem por principal objetivo estudar o processo de compreensão de conceitos e propriedades da Geometria Analítica do Ensino Médio com o uso do software GrafEq em uma turma de alunos do terceiro ano do Ensino Médio de uma escola da cidade de Santa Maria/RS. Neste recorte, enfatiza-se as atividades realizadas envolvendo os objetos reta e desigualdades. Essas atividades trataram da representação no GrafEq de imagens de prédios históricos de Santa Maria. Por meio delas, buscou-se explorar, principalmente, os tópicos: equação algébrica da reta, os seus coeficientes, o paralelismo entre retas e o registro gráfico do objeto reta. Outro aspecto abordado é o trabalho com desigualdades que é possibilitado pelo GrafEq, à medida que permite plotar regiões gráficas definidas por relações de inequações.

No segundo item apresentam-se mais algumas considerações sobre o software GrafEq que levam a acreditar no seu potencial para o processo de ensino e aprendizagem da matemática. No terceiro item apresentam-se reflexões teóricas sobre a Teoria dos Registros de Representação Semiótica de Raymond Duval, especialmente no que se refere ao processo de conversão, haja vista que essa transformação entre registros de representação é essencial para a compreensão dos objetos matemáticos. No quarto item, são apresentadas questões metodológicas referentes à pesquisa que origina $o$ presente trabalho. No item seguinte, faz-se a análise dos resultados de duas atividades que versam sobre os objetos reta e desigualdades. Os resultados apontam para uma contribuição dessas atividades para o reconhecimento e compreensão pelos alunos 
desses objetos nos seus registros de representação semiótica. No último item são encaminhadas as considerações finais do trabalho.

\title{
2 O Software GrafEq
}

Acredita-se que o uso do computador deve privilegiar as experimentações e o pensar do aluno, a construção do seu conhecimento, ou seja, o computador pode contribuir para a mobilização do aluno em busca da compreensão dos conceitos matemáticos. Nesse sentido, optou-se pelo trabalho com o GrafEq pois esse software pode contribuir para a aprendizagem dos conceitos da geometria analítica $\mathrm{e}$ desigualdades, à medida que possibilita plotar funções, equações, inequações e relações de inequações definindo regiões gráficas no plano cartesiano.

É importante ressaltar a possibilidade de o aluno conjecturar, testar, analisar e avaliar as suas construções no GrafEq. Gravina e Basso (2010) esclarecem sobre a importância desse processo.

\begin{abstract}
Ao controlar os efeitos de desenho a partir de manipulações algébricas, os alunos podem apreender sobre movimentos de gráficos. Desta forma, as expressões algébricas associadas ficam impregnadas de significado geométrico e isso é resultado das explorações feitas no sistema de representação que com seu dinamismo, de imediato, relaciona duas diferentes representações de um objeto - a analítica e a geométrica. (Gravina, Basso, 2010, p. 14).
\end{abstract}

Ainda, com relação às manipulações algébricas, pode-se trabalhar no GrafEq transformações como translações, reflexões, dilatações e contrações. Na imagem a seguir tem-se um exemplo de semicírculos transladados horizontalmente. A construção dos semicírculos pode ser realizada separadamente como indicado na construção (a) ou de forma mais complexa como na relação (b).

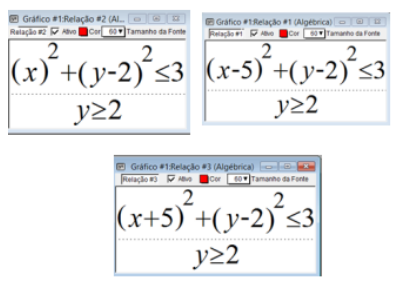

a

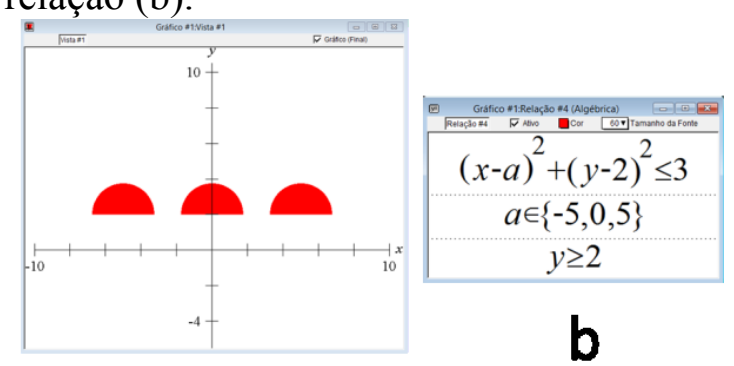

b

Figura 3 - Translação horizontal de semicírculos no GrafEq

A possibilidade de representação simultânea potencializa ao aluno discriminar as unidades significantes do registro algébrico (Duval, 2009), haja vista que graficamente evidencia que os semicírculos apresentam o mesmo raio e as origens dos semicírculos transladados horizontalmente apresentam a mesma ordenada.

Essas são algumas das características desse software que conduzem a acreditar que a utilização dessa ferramenta tecnológica pode possibilitar situações diferentes das habituais (trabalhadas somente com lápis e papel), e propícias para o processo de ensino e aprendizagem da geometria analítica.

\section{Os Registros de Representação Semiótica e a Compreensão dos Conceitos Matemáticos}

Os estudos de Raymond Duval alertam para a importância das representações semióticas na aprendizagem da matemática. Os objetos matemáticos, em geral, são expressos por meio de diferentes registros, tais como o registro algébrico com suas 
regras de funcionamento, o registro gráfico, com regras de tratamento que levam à identificação dos elementos pertinentes de uma figura e, dentro deste registro, inclui-se o de natureza gráfica, dado por sistema de coordenadas cartesianas e curvas que nele são traçadas, o registro discursivo em linguagem natural, e também com símbolos, com suas regras convencionais de comunicação (Duval, 2009).

Para Duval (2003) a compreensão ocorre a partir da coordenação das diversas representações semióticas de um mesmo objeto matemático. Segundo Duval (2009) o pensamento científico é inseparável do desenvolvimento de simbolismos que representam os objetos de estudo das ciências. No caso da matemática, esse fato é ainda mais evidente, afinal são muitas as formas de se representar um mesmo objeto matemático.

Devido à existência de diferentes representações semióticas para um mesmo objeto, é necessário estabelecer, então, de que forma se dá a coordenação de dois ou mais tipos. Essa é, na verdade, a questão fundamental do trabalho de Duval.

\subsection{Transformações de registros de representações semióticas}

Duval (2009) estabelece os dois tipos de transformações de representações semióticas - os tratamentos e as conversões. O tratamento refere-se à transformação que permanece num mesmo sistema de representação como, por exemplo, ao resolver a equação $3 x-7=5$ adotar apenas procedimentos algébricos, conforme ilustrado abaixo.

$$
\begin{gathered}
3 x-7=5 \\
3 x=5+7 \\
3 x=12 \\
x=\frac{12}{3} \\
x=4
\end{gathered}
$$

Na conversão há a passagem de um registro de representação para outro, mas conservando o mesmo objeto matemático. Como exemplo, podemos considerar a mudança do registro gráfico de uma reta para o seu registro algébrico ou vice-versa.

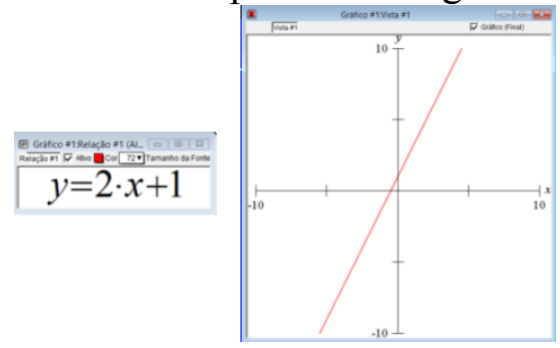

Figura 4 - Conversão dos registros algébrico e gráfico de uma reta

Do ponto de vista dos processos cognitivos referentes à compreensão, a conversão não deve ser tomada como uma simples tradução de um sistema em outro. No caso das representações semióticas de um conceito da geometria analítica, é necessária uma abordagem que permita realizar experimentos com os gráficos para compreender as relações algébricas e vice-versa.

Há, por trás da aplicação de uma regra de codificação para passar de uma equação a um gráfico cartesiano, a necessária articulação entre as variáveis cognitivas que são específicas do funcionamento de cada um dos dois registros. Pois são essas variáveis que permitem determinar quais as unidades de significado pertinentes, que devem ser levadas em consideração, em cada um dos registros de representação. (Duval, 2003, p. 17). 
Nesse sentido, verifica-se a importância que se deve dar ao processo de conversão no ensino da matemática. Para a compreensão de um objeto matemático é necessário que o aluno reconheça-o nos seus registros de representação, afinal eles contém conteúdos diferentes.

O conteúdo de uma representação depende mais do registro de representação do que o objeto representado. Porque passar de um registro de representação a outro não é somente mudar de modo de tratamento, é também explicar as propriedades ou os aspectos diferentes de um mesmo objeto. (Duval, 2003, p. 22).

Por exemplo, no registro algébrico da circunferência $(x+3)^{2}+(y-4)^{2}=9$, pode-se facilmente concluir que está centrada no ponto $(-3,4)$ e que possui raio igual a 3. Porém, a partir do seu registro gráfico é mais fácil observar que tangencia o eixo das ordenadas e que fica compreendida no segundo quadrante do plano cartesiano.

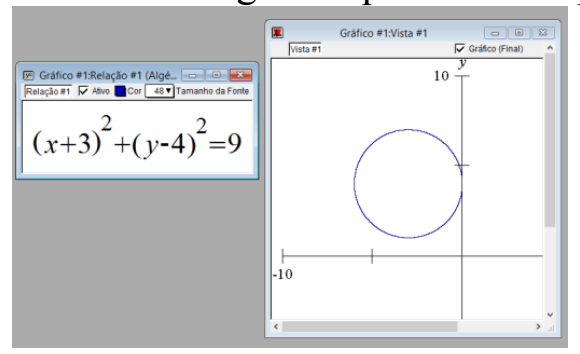

Figura 5 - Registros algébrico e gráfico de uma circunferência

A conversão não se esgota em mudar de registro de representação semiótica. Diferentes registros de um objeto matemático podem evidenciar propriedades ou aspectos desse mesmo objeto, ou seja, as representações semióticas de um mesmo objeto não possuem o mesmo conteúdo. Daí a necessidade de haver a coordenação de ao menos dois tipos de registros de representações semióticas para que os objetos matemáticos não se confundam com as próprias representações.

\section{Procedimentos Metodológicos e a Pesquisa Realizada}

A pesquisa foi realizada com uma turma de alunos do terceiro ano do Ensino Médio do Colégio Estadual Manoel Ribas localizado na cidade de Santa Maria/RS. Para o presente trabalho ater-se-á à análise de duas atividades propostas na sequência que versam sobre os objetos matemáticos reta e desigualdades. Tomando os pressupostos e resultados da Teoria dos Registros de Representações Semióticas, objetivou-se verificar se as atividades analisadas contribuem para a aprendizagem desses objetos e discutir de que modo isto aconteceu.

A pesquisa possui cunho qualitativo à medida que se está interessado em estudar os significados que os alunos atribuem para as diferentes representações semióticas dos objetos da geometria analítica. Segundo Moreira (2003) a principal característica da pesquisa qualitativa é a interpretação do pesquisador sobre os dados e informações coletadas, tanto que alguns autores preferem chamá-la de interpretativa. Os instrumentos de coleta de dados utilizados na pesquisa foram o diário de bordo do professor pesquisador e a produção dos alunos.

A escolha do Colégio Estadual Manoel Ribas para a realização da pesquisa deveu-se pelo fato de apresentar a infraestrutura necessária, além do interesse da equipe gestora da escola e dos alunos em participar da pesquisa. A turma escolhida possuía vinte e cinco (25) alunos frequentes durante o ano letivo de 2014. Sete (7) deles ausentaram-se em algumas aulas, tanto antes quanto durante o período da experimentação da sequência didática. Assim, optar-se-á em analisar as produções de 
dezoito (18) alunos que frequentaram de forma regular as aulas. Consiste em uma turma do Ensino Médio regular, cuja maioria dos alunos possuía de dezessete (17) a dezenove (19) anos. Em algumas aulas, fez-se necessário que fossem formadas algumas duplas devido ao número maior de alunos do que computadores disponíveis.

Sobre o conteúdo de geometria analítica, cabe salientar que a professora titular de Matemática já havia trabalhado com a turma o conteúdo de equação da reta, inclusive sobre o tópico coeficientes da equação da reta.

\section{Produções dos alunos, resultados e discussão: Geometria Analítica, GrafEq e a arquitetura de Santa Maria}

Além do conhecimento matemático, buscou-se integrar às atividades aspectos históricos e culturais da cidade de Santa Maria. Com essa escolha, acredita-se ter contribuído para o interesse dos alunos na realização das atividades e para que desenvolvessem um novo olhar para com a cidade na qual residem, passando a valorizar mais o seu patrimônio arquitetônico.

A primeira atividade analisada versa sobre a representação no GrafEq do portão de entrada do Colégio Estadual Manoel Ribas, escola na qual foi realizada a experimentação, que também é um prédio histórico da cidade.

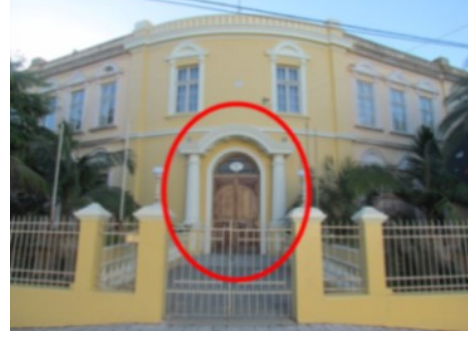

Figura 6 - Vista frontal do Colégio Estadual Manoel Ribas

Essa atividade demandou duas horas-aula para a sua dinamização. Os alunos primeiramente realizaram a construção dos elementos da região destacada que são delimitados por retas. As regiões delimitadas por circunferências foram construídas pelos alunos em uma etapa seguinte, mas que não será objeto de análise neste trabalho.

Como já se esperava, os alunos tiveram mais dificuldade em estabelecer as relações com as inequações correspondentes às colunas, principalmente quando identificaram que eram limitadas por retas não horizontais. Para estabelecer as primeiras equações dessas retas os alunos testaram os seus coeficientes. Por exemplo, para determinar os valores dos coeficientes angulares das retas, o aluno D realizou experimentações por tentativas: ora aumentava os seus valores ora diminuía, até que encontrou a representação gráfica desejada. Outra característica observada nos trabalhos, e que está presente na construção do aluno $\mathrm{D}$, corresponde à simetria das regiões estabelecidas em relação ao eixo das ordenadas, conforme a figura a seguir. Esta simetria está em consonância com a região a ser representada, destacada na figura 6 .

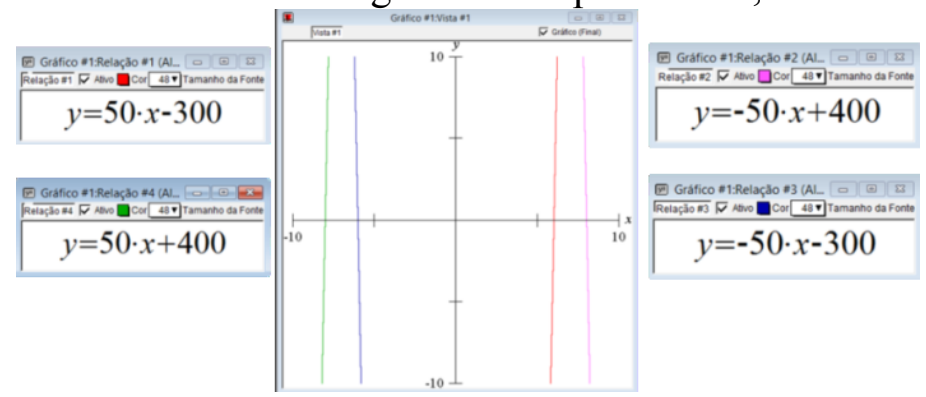

Figura 7 - Representação inicial realizada pelo aluno D 
É interessante observar a seguinte fala do aluno D:

Aluno D: Ah, se essa reta $(y=50 x-300)$ é assim, então para achar a do outro lado é só trocar o sinal.

$\mathrm{O}$ aluno havia conjecturado que se plotasse a reta $y=-50 x+300$ obteria a representação gráfica de uma reta paralela à anterior. A partir disso, solicitou-se que o aluno fizesse esse teste, conforme havia pensado. Ao plotar essa equação o aluno observou que o resultado gráfico não foi o esperado, pois não se tratavam de retas paralelas como pretendia representar. Assim, questionou-se o porquê desse fato, obtendo-se a seguinte resposta:

Aluno D: Acho que eu só preciso trocar um dos números (o sinal deles), vou ver qual deles que é.

Em seguida, o aluno testou e verificou que necessitava manter o mesmo coeficiente angular, pois assim geraria uma reta paralela à anterior. O passo final foi modificar o valor do coeficiente linear (nesse momento o aluno definiu a reta $y=$ $50 x+400)$ de modo que as colunas representadas no gráfico fossem simétricas em relação ao eixo das ordenadas.

Para Duval (2013), do ponto de vista cognitivo, compreender é:

\begin{abstract}
[...] primeiro reconhecer o mesmo objeto em diferentes representações semióticas que podem ser feitas a partir dele, cujos conteúdos não têm nada em comum. E isso significa pensar de forma espontânea, e por si só, em substituir uma dada representação semiótica por outra representação semiótica útil para um tratamento. Este aspecto é crucial para resolver qualquer problema. (Duval, 2013, p. 20).
\end{abstract}

Assim, pôde-se observar que o aluno D e os seus colegas, reconheciam parcialmente os coeficientes da equação de uma reta, porém ainda não diferenciavam o que representam graficamente. Nesse sentido, afirma-se que para esses alunos o reconhecimento desse objeto nos seus registros está em processo. Acredita-se que, por meio das explorações proporcionadas, esta atividade colaborou para a consolidação e aprendizagem dessas propriedades à medida que os alunos realizaram experimentos no GrafEq para validar ou refutar suposições feitas por eles.

A seguir apresenta-se a imagem com a construção final realizada pelo aluno D.

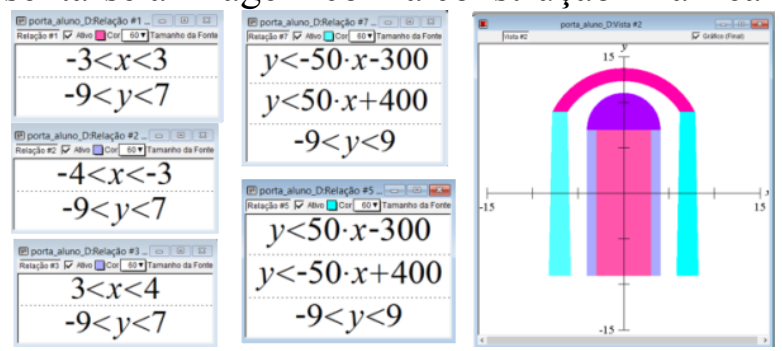

Figura 8 - Representação realizada pelo aluno D

Um fato constatado durante a realização dessa atividade (e também em atividades seguintes da sequência dinamizada) foi a não compreensão das desigualdades por parte de alguns alunos. Inclusive, alguns não sabiam diferenciar os signos maior $(>)$ e menor $(<)$. O que pode ser constatado quando necessitavam, por exemplo, estabelecer a relação algébrica que correspondia aos números (reais) maiores que dois, isto é, não conseguiam diferenciar as expressões $x>2$ e $x<2$. Outro fato que corrobora para essa afirmação consiste em observar nos arquivos finais das construções de alguns alunos que estes não adotam um padrão para registrar algebricamente uma região compreendida entre dois valores, conforme a figura a seguir. 


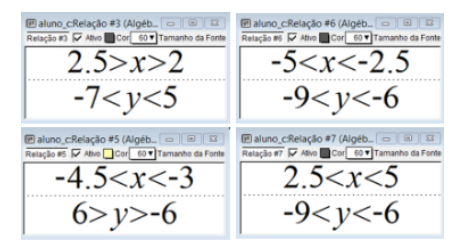

Figura 9 - Relações de inequações utilizadas pelo aluno C

Pode-se observar que em cada uma das relações da primeira coluna o aluno $\mathrm{C}$ utilizou uma relação do tipo $a<z<b$ e outra do tipo $c>w>d$. Esse aluno questionou o professor pesquisador durante a aula sobre algumas de suas tentativas de plotar relações algébricas que não haviam gerado os registros gráficos que desejava. Pôde-se constatar que, nesse caso, o aluno não compreendia as relações algébricas e o que elas representavam graficamente. $\mathrm{Na}$ atividade seguinte, o aluno $\mathrm{C}$ passou a definir todas as relações na forma $a<z<b$. Nessa perspectiva, pôde-se verificar que a atividade contribuiu para que o aluno reconhecesse essas desigualdades múltiplas enquanto regiões delimitadas por segmentos de retas.

Outros alunos também apresentaram essa dificuldade ao longo da experimentação da sequência didática, o que já era esperado, pois abordagens sobre desigualdades são poucos usuais no ensino da matemática, principalmente quando considerada a representação gráfica correspondente de cada relação de inequações. Sobre o trabalho com desigualdades no GrafEq, (Notare, Gravina, 2013, p. 7) afirmam que "em experiências com alunos, muitas vezes, detectamos conflitos cognitivos frente à aparente não resposta do software ao desenho de forma resultante de intersecções de conjuntos". No presente caso, observa-se que esses alunos não entendiam prontamente que a intersecção resultante da relação de inequações plotada é um conjunto vazio. $\mathrm{Na}$ experiência desenvolvida, esses conflitos foram sendo amenizados à medida que testavam suas conjecturas iniciais, avaliando os resultados das experimentações realizadas e por meio da interação com o professor e os próprios colegas.

Escolheu-se para a próxima atividade uma estrela que faz parte da decoração do teto da Catedral Diocesana de Santa Maria.

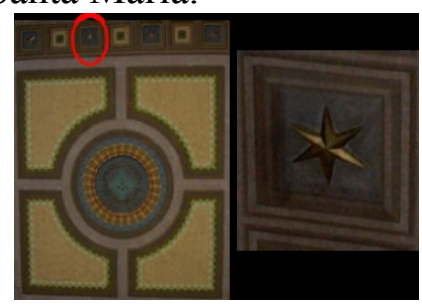

Figura 10 - Estrela presente na decoração do teto da Catedral

A atividade de representação dessa estrela no GrafEq demandou um período de cinco (5) horas/aula para que fosse completamente concluída. Os alunos apresentaram duas principais dificuldades, a saber: a definição das retas que delimitam as regiões que compõem a imagem e estabelecer as inequações para as relações algébricas.

Inicialmente, durante o primeiro encontro de duas (2) horas/aula, todos os alunos buscaram encontrar as equações das retas que delimitassem os braços da estrela por meio de tentativas de estabelecer os valores dos coeficientes da equação da reta.

No encontro seguinte (três horas/aula) questionaram-se os alunos sobre como poderiam obter a equação de uma reta específica do plano cartesiano. As respostas obtidas em nenhum momento indicaram um caminho viável e que convergisse para a utilização da equação geral da reta. Dessa forma, pôde-se observar que, mesmo que tenham realizado um estudo preliminar sobre este tópico, estes alunos não associavam aquilo que haviam estudado com a situação colocada, ou seja, que se pode obter a 
equação de uma reta por meio da fórmula $y-y_{a}=m\left(x-x_{a}\right)$, onde $\left(x_{0}, y_{0}\right),\left(x_{1}, y_{1}\right)$ e $\left(x_{a}, y_{a}\right)$ são pontos da reta e $m=\frac{y_{1}-y_{0}}{x_{1}-x_{0}}$. Assim, entende-se que os alunos ainda não compreendiam, de fato, o que representa uma reta nos seus diversos registros de representação (Duval, 2013).

Em seguida, o professor pesquisador optou em realizar na lousa em conjunto com os alunos o estudo de um exemplo de determinação da equação de uma reta cujo gráfico foi fornecido no GrafEq e escolhidos dois pontos a ele pertencentes. Essa resolução conjunta ajudou-os a determinar as equações das retas que compõem a estrela. A figura a seguir apresenta os tratamentos algébricos realizados pelo aluno $\mathrm{E}$ depois de determinar os pontos $A(5 ; 0)$ e $B(10,5 ;-9,35)$.

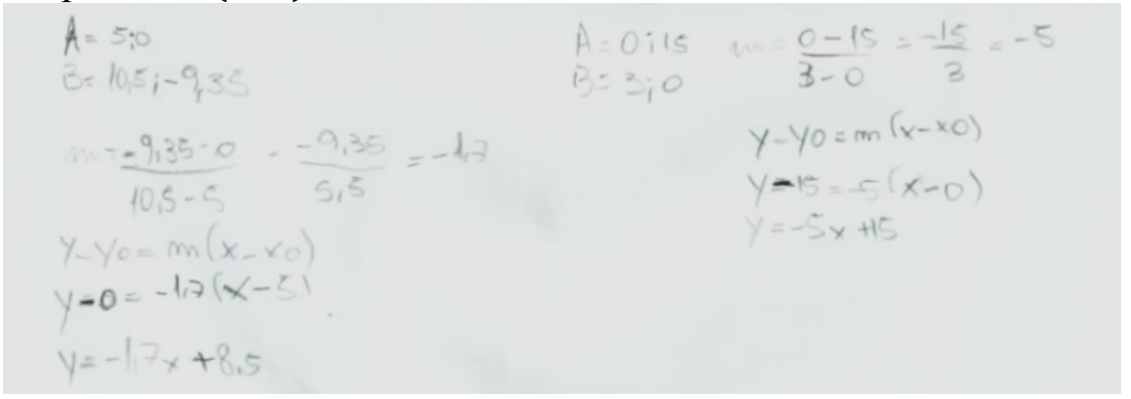

Figura 11 - Tratamento realizado pelo aluno E

Dessa forma, pôde-se observar que mesmo os alunos, que haviam durante as aulas anteriores, resolvido problemas enunciados no livro didático ou propostos pela professora titular em que necessitavam estabelecer a equação de uma reta, não conseguiram transpor esse conhecimento para uma situação semelhante. Pois, conforme já se afirmou, segundo Duval $(2009,2013)$, os alunos ainda não pensavam de forma instantânea, ou seja, não substituíam a representação gráfica pela sua representação algébrica correspondente de modo que pudessem realizar os necessários tratamentos algébricos para encontrar as equações das retas e, consequentemente, as relações de inequações que definem as regiões gráficas.

A partir desta intervenção os alunos passaram a realizar sistematicamente o processo de identificar dois pontos pertencentes ao gráfico de uma reta e, em seguida, realizar os devidos tratamentos algébricos para encontrar a equação dessa reta. A figura a seguir apresenta a construção final do aluno $\mathrm{E}$.

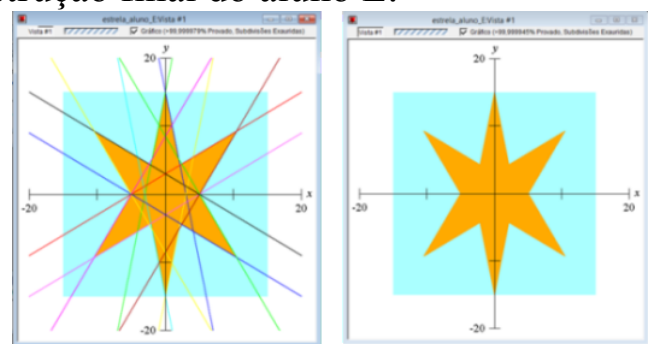

Figura 12 - Estrela construída pelo aluno E

À esquerda encontram-se visíveis todas as retas que delimitam os braços da estrela.

\section{Considerações Finais}

O presente trabalho pretendeu realizar, de forma sucinta, uma análise dos principais resultados de uma experiência com uma turma de alunos do terceiro ano do Ensino Médio. Trata-se de um recorte da pesquisa de mestrado do autor que discute uma sequência didática elaborada com base na Teoria dos Registros de Representação Semiótica de Raymond Duval utilizando o software GrafEq. 
Ao se analisar as duas atividades, pôde-se verificar que estas proporcionaram aos alunos um estudo diferenciado em relação ao já realizado. Em um primeiro momento, os alunos apresentaram dificuldades relacionadas à compreensão da coordenação das representações semióticas dos objetos reta e desigualdades. Porém, mostraram-se interessados e, sobretudo, engajados com a resolução das atividades.

Buscou-se na dinamização das atividades promover a interação entre os próprios alunos e do professor pesquisador com os alunos. Quando não obtinham o resultado gráfico desejado após plotar uma relação algébrica, os alunos questionavam sobre o porquê desse resultado. Esse é um indício de que realmente essa ferramenta possibilitou aos alunos diferentes experimentações, haja vista que realizavam conjecturas, avaliavam-nas, testavam-nas, reavaliavam-nas ou refutavam-nas.

Do ponto de vista cognitivo, ressalta-se que houve um avanço na compreensão dos objetos reta e desigualdades ao longo da experimentação. De forma geral, a partir da primeira atividade, os alunos passaram a relacionar o que as alterações realizadas nos coeficientes da equação da reta representam graficamente. $\mathrm{Na}$ segunda atividade, explorou-se principalmente a conversão do registro gráfico da reta para o seu registro algébrico a partir do reconhecimento gráfico de dois pontos (variáveis visuais). Além disso, por meio de ambas as atividades os alunos realizaram experimentações para reconhecer o objeto desigualdades nos registros gráfico e algébrico. Dessa forma, não se trata de dizer que os alunos compreendem o objeto reta de uma forma plena. O que se tem são indícios que as atividades propostas com o uso do GrafEq contribuíram para o processo de reconhecimento desse objeto nos seus registros de representação semiótica.

Por tudo isso, ao fim desse trabalho, pode-se dizer que a experiência foi de grande valia tanto para os alunos sujeitos da pesquisa quanto para a formação dos pesquisadores. Acredita-se que a proposta apresentada possa servir como base para novas experiências em sala de aula, em especial, no ensino da geometria analítica.

\section{Referências}

DUVAL, R. Registros de representações semiótica e funcionamento cognitivo da compreensão em matemática. In: MACHADO, S.D.A. (Org.). Aprendizagem em matemática: registros de representação semiótica. Campinas: Papirus, 2003. p. 11- 33. DUVAL, R. Semiósis e Pensamento Humano. Tradução: Lênio Fernandes Levy, Marisa Rônsani Abreu da Silveira. São Paulo: Livraria da Física, 2009. 110 p. DUVAL, R. Raymond Duval: depoimento [2013]. Entrevistadores: J.L.M. de Freitas e V. Rezende. Campo Mourão: RPEM, 2013. Revista impressa. Entrevista concedida a Revista Paranaense de Educação Matemática, v. 2, n. 3, jul-dez 2013. GRAVINA, M. A; BASSO, M. V. de A. Mídias digitais na Educação Matemática. In: GRAVINA, M. A. et al. (Org.). Matemática, Mídias Digitais e Didática - tripé para formação de professores de Matemática. Porto Alegre: UFRGS, [2010]. p.13.

Disponível em: <http://www.ufrgs.br/espmat >. Acesso em: 5 abr. 2015.

MOREIRA, M.A. Pesquisa em ensino: aspectos metodológicos. In: Instituto de Física UFRGS. Burgos: Universidade de Burgos, 2003. Disponível em:

$<$ http://www.if.ufrgs.br/ moreira/pesquisaemensino.pdf $>$. Acesso em: 18 fev. 2015. NOTARE, M. R.; GRAVINA, M. A. A formação continuada de professores de matemática e a inserção de mídias digitais na escola. In: VI colóquio de história e tecnologia no ensino de matemática, 10, 2013, São Carlos. Anais. 2013. NOTARE, M. R.; FIOREZE, L. A. A; HALBERSTADT, F.F. O software GrafEq e os registros de representação semiótica: uma análise de trabalhos com ilusão de ótica. In: XIV Conferência Interamericana de Educação Matemática, 12, 2015, Tuxtla Gutiérrez. Anais. 2015. 